\title{
Application of Supercapacitors to Drive Electric Vehicle
}

\author{
${ }^{*}$ Prasit Phoosomma ${ }^{1}$, Prayut Nisapakul ${ }^{2}$, and Kitti Korbuakaew ${ }^{3}$ \\ ${ }^{1,2}$ Department of Electrical Technology, Faculty of Science and Technology, Dhonburi Rajabhat University, \\ Thonburi, Bangkok, 10600 Thailand \\ ${ }^{3}$ Industrial Management Department, Faculty of Science and Technology, Dhonburi Rajabhat University, \\ Thonburi, Bangkok, 10600 Thailand
}

\begin{abstract}
This paper focuses on the energy management in a fast charging station for supercapacitors (SCs) alone and storage device in electric vehicle (EV). The main objective to minimize the duration of the battery charging process and the time. The operation model of the energy storage system and the power supply by supercapacitors to driving electric vehicles. The capacity of a supercapacitors that can be used to drive an electric vehicle of 4 seats. The advantages of supercapacitors are high power density, high efficiency, fast charging and discharging speed, long cycle life, wide operating temperature range and environment friendly. The results show that charge and discharge at voltage rated 48-V, 10-A maximum efficiency of $98.88 \%$. For charging and discharging at the current rated 100-A, the efficiency lower of $91.74 \%$. The driving electric vehicles with a supercapacitor at a total weight of 405 $\mathrm{kg}$ can be driven to the distance of 1150 meters, take time of 6 minutes 21 seconds and average speed $10.86 \mathrm{~km} / \mathrm{h}$. Using supercapacitors as a power source to driven at a total maximum weight of $480 \mathrm{~kg}$ at the current 20.33-A, time of 7 minutes, 27 seconds and power of 798.29-W. The supercapacitors can be driven to a distance of 1010 meters, it takes time 5 minutes, 15 minutes and the average constant speed of $11.54 \mathrm{~km} / \mathrm{h}$. The power to drive 822.47-W, to achieve the highest efficiency $97.06 \%$. This system proposed the implemented effectively renewable energy resource.
\end{abstract}

Keywords: Charging and Discharging, Electric Vehicle, Supercapacitors 


\section{Introduction}

The battery is an essential electronic energy storage unit which is applied in many devices such as portable flashlights, remote controls, mobile phones, laptops, electric vehicles, and photovoltaics. Also, the battery is the ideal solution for the development of hybrid electric vehicle (HEV). However, the battery has the limitation that can be chemically stored for its intended use. In the other hand, it can not created new powers for themselves. Charging necessary when the battery is recharging for several hours, and recharging only $80 \%$ efficient. Typical battery for car cranking designes to deliver a high amount of energy in very short period of time. If one crank uses more than $20 \%$ or $30 \%$ of energy storage, it will reduce the lifetime of the battery. Also, after several turns of the recharging process, the effective of the battery will be reduced over time. A battery also considered as a high-cost component and fragile. In cause if it is not cared for or used properly. However, different lifetime cycles of a battery are dependent on usage, the charging/discharging processing and activing ambient temperature. The battery in uninterruptedly power supply (UPS) has a lifetime period of 3 to 4 years or 500 to 600 cycles at $50 \%$ discharging before a replacement needed to assure its reliability $[1,11,12]$.

High-performance capacitors or electrochemical double-layer capacitors (EDLCs), commonly known as Ultracapacitors or Supercapacitor (SC), are used to store electrical energy by its rapidly charging The SC also is used to co-operate with battery to reduce charging time and also enhance the performance of the battery in storing energy because of its low charging time and thermal loss which result in low energy loss and extended battery lifetime. Which SC have high lifetime cycles about 1 million cycles [2]. The purposes of this paper were to solve the problem of long-time battery charging and high cost of battery replacement. 


\section{Materials and Methods}

\subsection{General (using batteries)}

The original circuit to consist of ac power source, charger, batteries, and electric vehicle. The general include lead-acid battery TROJAN size 12V, 120AH, life 2 years or 500 cycle, with high energy density properties. There are limit on the current to charge and high cost of battery replacement, as shown in Figure. 1

This research was conduct at Dhonburi Rajabhat University, Samutpakan. It the total area more than is 102 acre, there are 14 buildings.

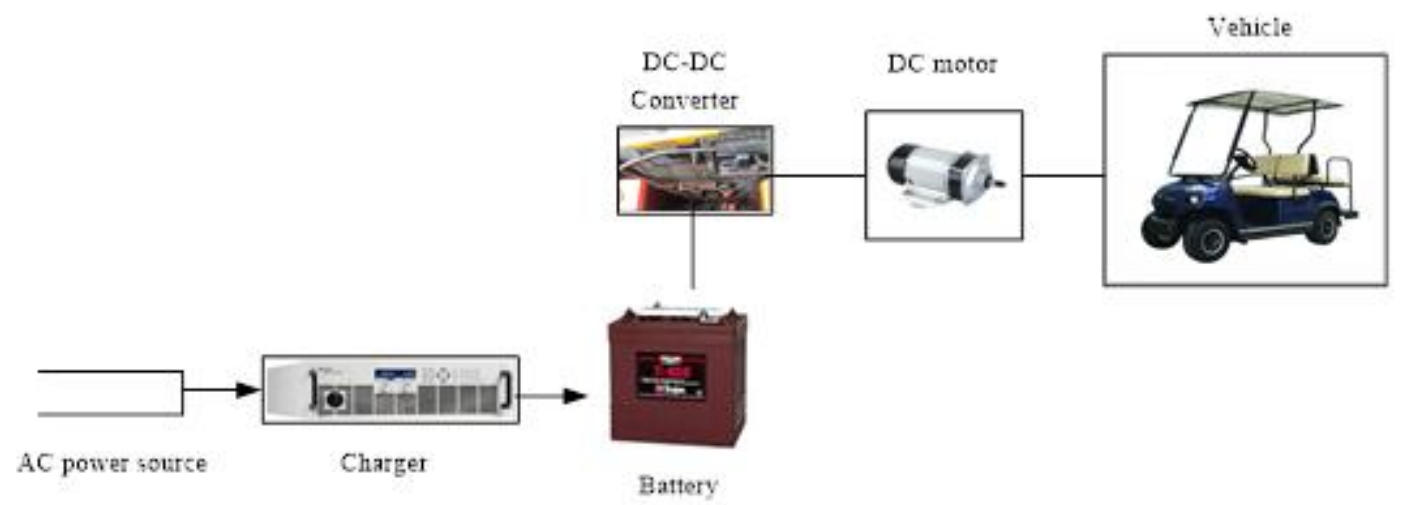

Figure 1. The structure of the original electric vehicle drive system.

\subsection{Synthesis (add to SCs)}

Synthesis systems have been considered for the following: 1)165F, 48V Maxwell supercapacitors, and 2) The generator for electric vehicle regenerative.

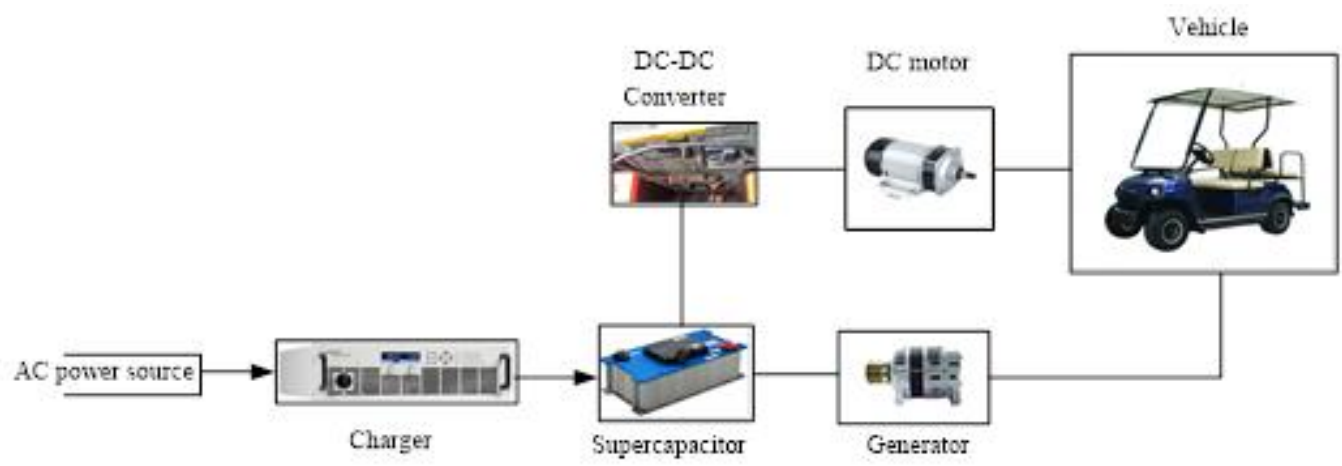

Figure 2. New electric vehicle propulsion system structure. 
Based on the study of charging / charging and electric vehicle propulsion with SC, research has been conducted as following:

1. Electric vehicle drive system design

The design of this electric vehicle propulsion system shows the working model of the supercapacitor power supply and distribution system to the dc motor used as a power transmission to the electric vehicle wheels. And connected to a DC generator braking or decelerating brakes, the generator will charge electric energy to the supercapacitor as shown in figure. 3

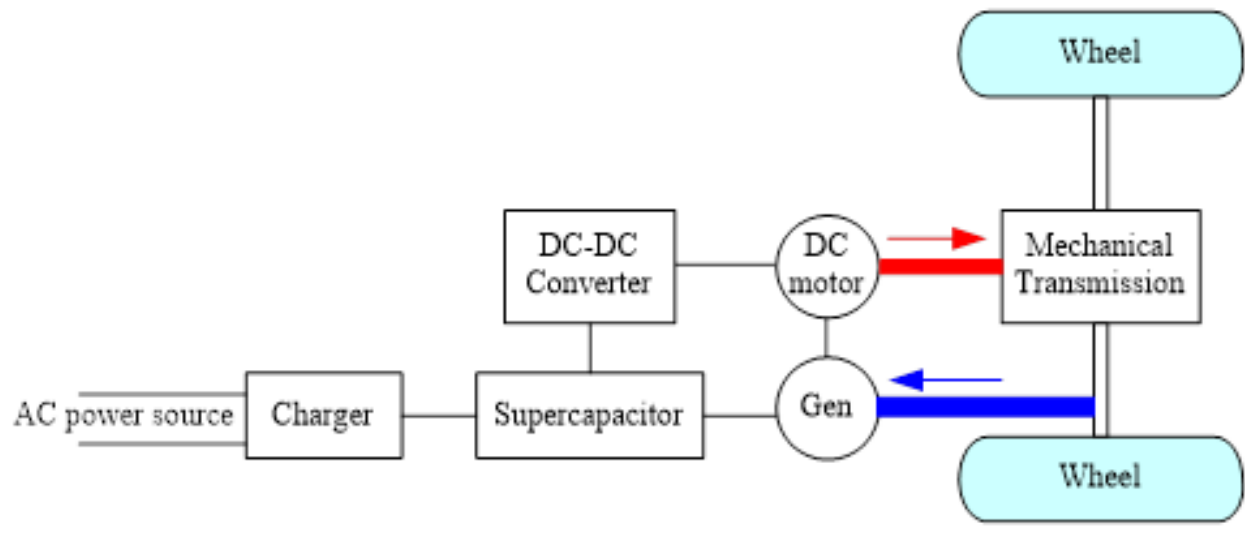

Figure 3. Diagram of electric vehicle propulsion

2. Design the capacity of the supercapacitor.

Designing a super capacitor capacity that can be used with a 4-seater, $290-\mathrm{kg}$ in total vehicle weight and 400 kilograms of total load to be used to run between the school building 4 to the library building. Dhonburi Rajabhat University, Samutprakan, with a distance of 505 meters per trip and a total distance of 1010 meters, which can be used to calculate the size of supercapacitors used to drive electric vehicles. To be able to run more than 505 meters as follows.

Choosing a supercapacitor size $165-\mathrm{F}, 48-\mathrm{Vdc}, 2$ banks, total capacity is $330-\mathrm{F} 48-\mathrm{Vdc}, 1$ set. 
3. The amount of time that can be run.

From the power formula (W) of the Super Capacitor, it can be used to find the time (t) that is used to drive electric vehicles as follows.

$$
\begin{aligned}
& \mathrm{E}=\frac{\frac{1}{2} \times \mathrm{C} \times \mathrm{V}^{2}}{3,600} \\
& \mathrm{E}=\frac{\frac{1}{2} \times 330 \times 48^{2}}{3,600}=380,160 \text { Joules }
\end{aligned}
$$

From the formula for electricity consumption.

$$
P=\frac{E}{t}
$$

When the rated of the DC motor, $\mathrm{P}=2000 \mathrm{~kW}$

How long the electric vehicle can run.

$$
\mathrm{t}=\frac{380160}{2000}=190.08 \sec (3 \text { minutes and } 10 \text { second })
$$

4. Distance electric vehicles can running.

From the circumference or wheel of the golf cart, there is a distance of 3.7 meters/cycle, speed of electric vehicles is $12 \mathrm{~km} /$ hour or 54 cycles/minute. Find distance to run per minute to get 200 meters/minute. Therefore, from using 1 set of supercapacitors $330 \mathrm{~F}, 48 \mathrm{~V}$, electric vehicles can run a distance of 633.6 meters.

\section{Charging time.}

Because supercapacitors can be charged at high currents and charged at rated voltages. Which can find the time and current used to charge the supercapacitor as in equation 3

$$
\mathrm{t}=(\mathrm{C} / \mathrm{I})
$$


Table 1: Current and charging time of supercapacitors

\begin{tabular}{|c|c|c|}
\hline Current $(\mathrm{A})$ & Percentage $(\%)$ & Charging time (sec) \\
\hline 1900 & 100 & 2 \\
\hline 950 & 50 & 19 \\
\hline 100 & 5.26 & 21 \\
\hline 90 & 4.74 & 23.75 \\
\hline 80 & 4.21 & 27.14 \\
\hline 70 & 3.68 & 32 \\
\hline 60 & 3.16 & 38 \\
\hline 50 & 2.63 & 47.50 \\
\hline 40 & 2.10 & 63.33 \\
\hline 30 & 1.57 & 95 \\
\hline 20 & 1.05 & 190 \\
\hline 10 & 0.53 & \\
\hline & & \\
\hline
\end{tabular}

\section{Data analysis}

1. Analyze measured current, voltage and energy in charging and discharging process of the SC

$$
\begin{gathered}
\mathrm{W}_{\mathrm{t}}=\int_{0}^{\mathrm{t}} \mathrm{pdt}=\int_{0}^{\mathrm{t}} \mathrm{I} \mathrm{v}_{\mathrm{c}} \mathrm{dt}=\int_{0}^{\mathrm{t}}\left(\mathrm{C} \frac{\mathrm{dv}}{\mathrm{dt}}\right) \mathrm{v}_{\mathrm{c}} \mathrm{dt}=\mathrm{C} \int_{0}^{\mathrm{t}} \mathrm{vdv} \\
\mathrm{W}_{\mathrm{c}}=\frac{1}{2} \mathrm{CV}_{\mathrm{c}}^{2}
\end{gathered}
$$


$\mathrm{W}_{\mathrm{c}}$ is the amount of energy stored in the SC (Joules; $\mathrm{J}$ )

$\mathrm{C}$ is the capacitance (Farads; F)

$\mathrm{V}_{\mathrm{c}}$ is the voltage level of the Capacitor (Volts; V)

Energy stored in the SC can be calculated as following Equation.

$$
\Delta \mathrm{W}\left(\mathrm{W}_{\mathrm{t}}\right)=\frac{1}{2} \mathrm{C}\left(\mathrm{V}_{1}^{2}-\mathrm{V}_{2}^{2}\right)
$$

When V1 is the Charge Voltage (V)

V2 is the Discharge Voltage (V)

2. Analyze the efficiency of the SC from the Equation (5) by using the collected voltage and current data from data logger to plot a graph and analyses the characteristics of change in voltage and current by time, use the data to calculate stored energy in the SC by the energy from the Equivalent series resistance (ESR) and calculate power loss from

$$
\mathrm{W}_{\mathrm{R}} \quad=\mathrm{I}^{2} \mathrm{Rt}
$$

The Equivalent series resistance (ESR)

$$
(E S R)=\frac{V_{f}-V_{\min }}{I_{d}}
$$

From Equation (3) and (4), we can calculate the efficiency of the SC.

The efficiency of the SC.

$$
(\eta)=\frac{\mathrm{W}_{\mathrm{c}}}{\mathrm{W}_{\mathrm{t}}}=\frac{\mathrm{W}_{\mathrm{c}}}{\mathrm{W}_{\mathrm{c}}+\mathrm{W}_{\mathrm{R}}}
$$

2. Analyze the data using SC as the secondary power supply with the designed circuit and then using the data from data logger to plot a graph to analyze the characteristics of change in voltage and current of the charging/discharging process by time using the data to calculate the stored energy in the SC and then the efficiency. 
4. Analyze the data using UPS battery as the secondary power supply then using the data from data logger to analyze the characteristics of change in voltage and current of the charging/discharging process by time.

The efficiency of the B.

$$
(\eta)=\frac{\mathrm{P}_{\text {out }}}{\mathrm{P}_{\mathrm{in}}}
$$

5. Analyze the data using the $\mathrm{SC}$ with the $\mathrm{B}$ as the secondary power supply then using the data from data logger to analyze the characteristics of change in voltage and current of the charging/discharging process by time.

\section{Results}

\subsection{Experimental procedures}

A study of energy storage behavior of supercapacitors. Experiment to drive the electric vehicle. The research processes is as follows;

1) The efficiency test of the supercapacitor by charging and discharging.

The experimental charging and discharging of the supercapacitors are as follows;

The constant voltage as $10 \mathrm{~V}$ and changing the current level of $10 \mathrm{~A}, 20 \mathrm{~A}, 30 \mathrm{~A}, 40 \mathrm{~A}, 50 \mathrm{~A}$, 60A, 70A, 80A, 90A and 100A, respectively.

Table 2: The data charging and discharging at constant voltage $48 \mathrm{~V}$, current $10 \mathrm{~A}, 20 \mathrm{~A}, 30 \mathrm{~A}, 40 \mathrm{~A}, 50 \mathrm{~A}$, 60A, 70A, 80A, 90A and 100A.

\begin{tabular}{|c|l|l|l|l|l|l|l|l|l|}
\hline \multicolumn{1}{|c|}{$\mathrm{V}_{\mathrm{w}}$} & $\mathrm{V}_{\mathrm{f}}$ & $\mathrm{V}_{\text {min }}$ & $\mathrm{I}_{\mathrm{d}}$ & $\mathrm{ESR}$ & $\mathrm{t}_{\text {charge }}$ & $\mathrm{t}_{\mathrm{d}}$ & $\mathrm{W}_{\mathrm{s}}$ & $\mathrm{W}_{\mathrm{d}}$ & \\
$(\mathrm{V})$ & $(\mathrm{V})$ & $(\mathrm{V})$ & $(\mathrm{A})$ & $(\Omega)$ & $(\mathrm{sec})$ & $(\mathrm{sec})$ & $($ Joule $)$ & $($ Joule $)$ & $(\%)$ \\
\hline 47.97 & 0.97 & 0.67 & 10 & 0.03 & 1075 & 790 & 278,425 & 210,140 & 98.88 \\
\hline 47.98 & 35.47 & 34.16 & 20 & 0.065 & 501 & 137 & 231,036 & 29,185 & 96.28 \\
\hline
\end{tabular}




\begin{tabular}{|l|l|l|l|l|l|l|l|l|l|}
\hline 47.99 & 34.18 & 32.77 & 30 & 0.047 & 482 & 149 & 203,034 & 93,344 & 93.67 \\
\hline 47.99 & 38.18 & 37.18 & 40 & 0.025 & 290 & 113 & 225,480 & 59,035 & 92.88 \\
\hline 47.98 & 41.04 & 40.31 & 50 & 0.015 & 201 & 82 & 181,169 & 27,989 & 90.34 \\
\hline 47.99 & 35.90 & 35.34 & 60 & 0.010 & 197 & 135 & 223,519 & 81354 & 94.01 \\
\hline 47.97 & 40.86 & 40.46 & 70 & 0.0057 & 164 & 81 & 209,326 & 48,216 & 95.52 \\
\hline 47.98 & 42.34 & 41.90 & 80 & 0.005 & 141 & 67 & 210,884 & 38,654 & 94.74 \\
\hline 47.98 & 35.87 & 35.37 & 90 & 0.005 & 146 & 134 & 230,804 & 75,879 & 93.32 \\
\hline 47.98 & 35.87 & 35.37 & 100 & 0.005 & 127 & 53 & 226,465 & 29,417 & 91.74 \\
\hline
\end{tabular}

2) The efficiency determine of supercapacitor

The efficiency of supercapacitor, $\eta_{S C}=\frac{\sum\left(V_{\text {out }} \times I_{\text {out }}\right)}{\sum\left(V_{\text {in }} \times I_{\text {in }}\right)} \times 100 \%$

$$
=\frac{21,0140}{278,425} \times 100 \%=98.88 \%
$$

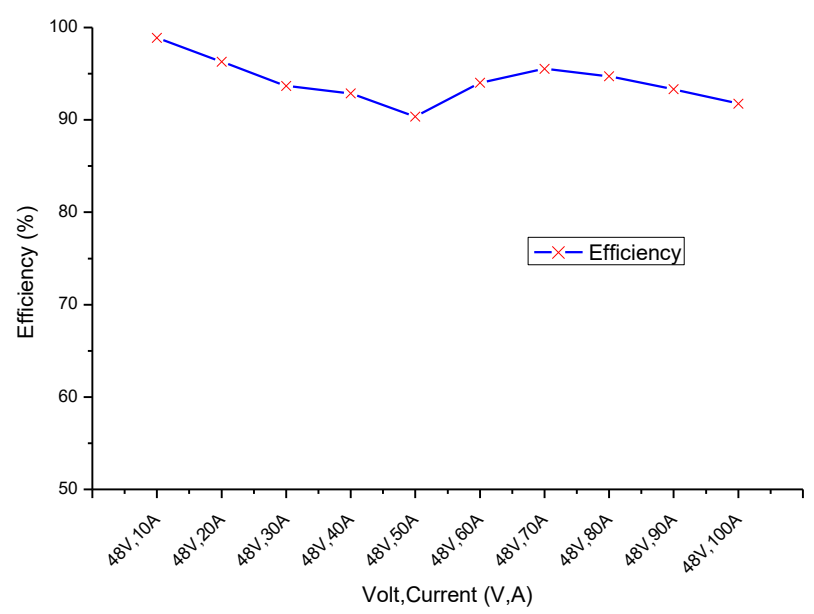

Figture 4. Supercapacitor efficiency 
3) The analysis uses a super capacitor to drive electric vehicles.

The results of analyzes use supercapacitors as energy sources instead of batteries to drive electric vehicles. By running the test back and forth between the station 1 and station 2, of Dhonburi Rajabhat University, Samutprakan, which has a distance of 505 meters per trip and a total distance of 1010 meters, as shown in figure 5.

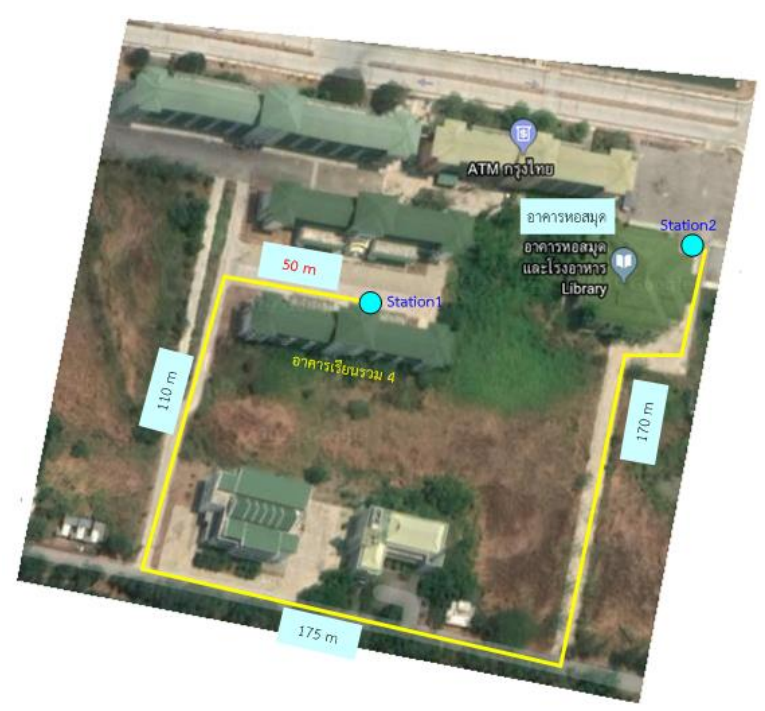

Figure. 5 Diagram of the experimental run of electric vehicles.

4) The results of the analysis of the efficiency of electric vehicles

The installation of supercapacitors to drive electric vehicles by testing the charging current at various values. Then, running along the actual route resulted in the highest efficiency of $97.06 \%$, at the charging current of $20.33 \mathrm{~A}$ and when the charging current increased at $79.15 \mathrm{~A}$, the efficiency would be reduced to $17.26 \%$. 


\begin{tabular}{|c|c|c|c|c|c|}
\hline \multirow[t]{2}{*}{$\begin{array}{r}\text { Charge current } \\
\text { (A) }\end{array}$} & \multicolumn{2}{|c|}{$\begin{array}{l}\text { Time } \\
\text { (sec) }\end{array}$} & \multirow{2}{*}{$\begin{array}{l}\text { Energy } \\
\text { stored } \\
\text { (Watt) }\end{array}$} & \multirow[t]{2}{*}{$\begin{array}{l}\text { Energy released } \\
\text { (Watt) }\end{array}$} & \multirow[t]{2}{*}{$\begin{array}{l}\text { Efficien } \\
\text { cy }(\%)\end{array}$} \\
\hline & charge & discharge & & & \\
\hline $20.33 \mathrm{~A}$ & 447 & 315 & 798.29 & 822.47 & 97.06 \\
\hline $39.53 \mathrm{~A}$ & 310 & 388 & 896.92 & 1459.30 & 61.46 \\
\hline $57.41 \mathrm{~A}$ & 238 & 313 & 743.39 & 2484.53 & 29.92 \\
\hline $79.15 \mathrm{~A}$ & 222 & 381 & 591.78 & 3428.44 & 17.26 \\
\hline
\end{tabular}

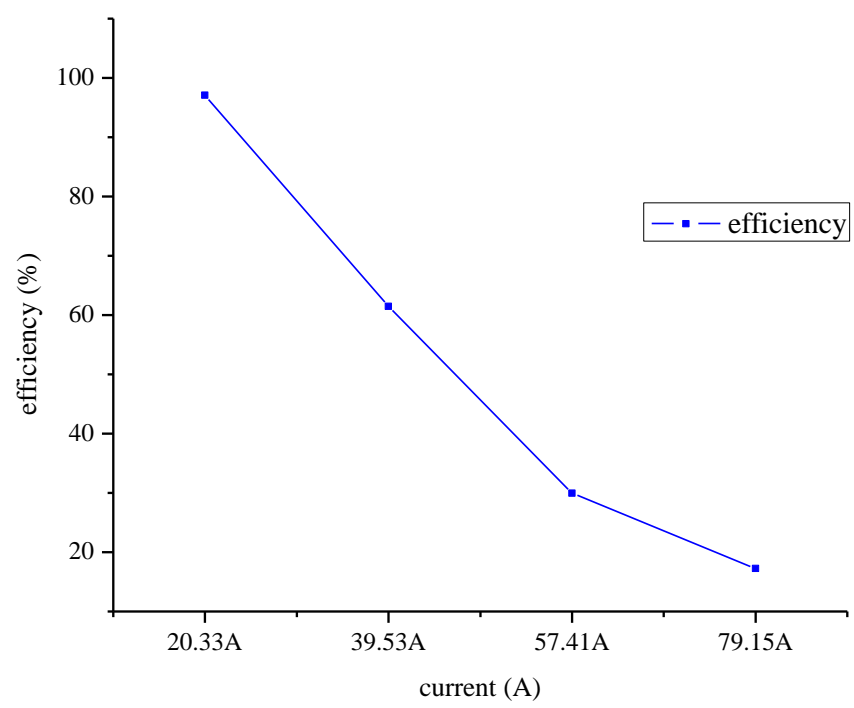

Figure 5. Efficiency in driving electric vehicles

4.2 Analysis results using supercapacitors and electric vehicle propulsion 


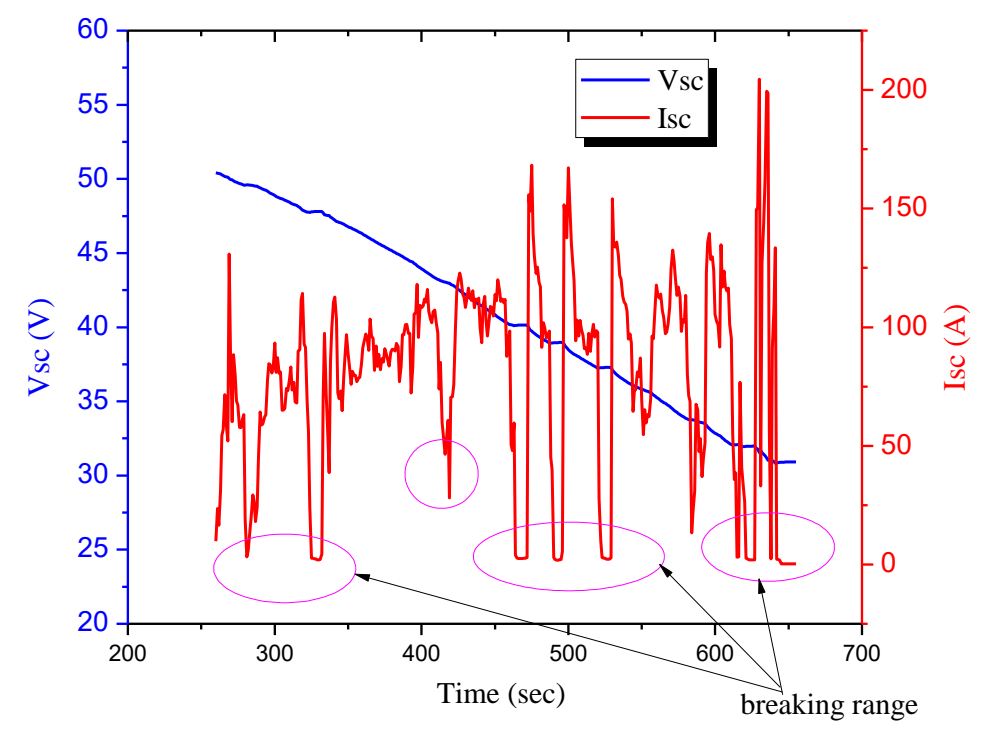

Figure 6. Voltage current, braking and slowing of brakes

\section{Conclusion}

The results of this research result in a Renewable energy that can recycle more than one million cycles and not pollute the environment. When considering the parameters from the experiment results and calculations Shows the performance of the super capacitor as a power source for driving electric vehicles. The analysis result uses supercapacitors as power sources to drive electric vehicles. With a total load of $480 \mathrm{~kg}$. Supercapacitors can drive an electric vehicle for 5 minutes 15 minutes. The distance of the test 1010 meters. During the test, run with braking or slow braking, found that the supercapacitor router is recharged at a voltage of $31.06 \mathrm{~V}$ from the installation of the charger.

\section{Acknowledgments and Legal Responsibility}

This research was provided financial supported the National Research council of Thailand. The author would like to thank Asst. Prof. Yuwaluk Wechwittayakhung, President of Dhonburi Rajabhat University support place and laboratory. 


\section{References}

[1] Prasit P., Nat K. and Narong M. (2019). Combination of Supercapacitor and AC Power Source in Storing and Supplying Energy for Computer Backup Power.

J. Electr. Eng. Technol., Vol. 14, NO.2, pp. 993-1000, DOI 10.1007/s42835-018-000700 .

[2] J. Cao,. and A. Emadi, (2012). “A New Battery/ Ultracapacitor Hybrid Energy Storage System for Electric, Hybrid, and Plug-In Hybrid Electric Vehicles",IEEE TRANSACTIONS ON POWER ELECTRONICS, Vol. 27, NO. 1, pp. 122-132.

[3] Dong-Hoon Hwang, Jung-Won Park, Jae-Han Jung. (2011). A Study on the Life time Comparison for Electric Double Layer Capacitors Using Accelerated Degradation Test. Gyeonggi-do, Korea.

[4] A. Hammar, P. Venet, R. Lallemand, G. Coquery, and G. Rojat. (2010). Study of Accelerated Aging of Supercapacitors for Transport Applications. IEEE TRANSACTIONS ON INDUSTRIAL ELECTRONICS, VOL. 57, NO. 12, pp. 39723979.

[5] M. Jayalakshmi and K. Balasubramanian, (2008). Simple Capacitorsto Supercapacitors An Overview. Int, J. Electrochem. Sci., Vol. 3, pp. 1196-1217.

[6] C. Jens, Schroeder, Bjoern Wittig, W. Friedrich Fuchs, (2010). High Efficient Battery Backup System for Lift Trucks Using Interleaved-Converter and Increased EDLC Voltage Range. Kaiserstr. Kiel, Germany, pp. 2334-2338.

[7] Jisheng Hu Yukun Zhao and Xiaojing Liu. (2008). The design of regeneration braking system in light rail vehicle using energy-storage Ultracapacitor. Dalian, Liaoning Province, China.

[8] Katsuhiro Hata, Naoya Watanabe and Kyungmin Sung. (2010). A Series or Parallel Changeover System Using Battery with EDLC for EV. Nakane, Hitachinaka, Ibaraki, Japan.

[9] J. Li, Y. Chen and Y. Liu, (2012). "Research on a Stand-alone Photovoltaic System with a Supercapacitor as the Energy Storage Device”, Energy Procedia, Vol. 16, No. 11, pp. 1693-1700. 
[10] A. Mirzaei, A. Jusoh, Z. Salam, E. Adib and H. Farzanehfard. (2010). Analysis and Design of a High Efficiency Bidirectional DC-DC Converter for Battery and Ultracapacitor Applications. Johor Bahru, Malaysia.

[11] Rares Bodnar, William Redman-White. (2011). A 250W/30A Fast Charger for Ultracapacitors with Direct Mains Connection. University of Southampton Southampton, UK. pp. 813-816.

[12] Jia, H.; Mu, Y.; Qi, Y. 2014. A statistical model to determine the capacity of batterysupercapacitor hybrid energy storage system in autonomous microgrid. Int. J. Electr. Power Energy Syst., 54, pp. 516-524.

[13] Khaligh, A.; Li, Z. (2010). Battery, Ultracapacitor, Fuel Cell, and Hybrid Energy Storage Systems for Electric, Hybrid Electric, Fuel Cell, and Plug-In Hybrid Electric Vehicles: State of the Art. IEEE Trans. Veh. Technol., 59, pp. 2806-2814. 